\title{
INFLUENCE OF NANO-BENTONITE IN HYDRAULIC CONDUCTIVITY PERFORMANCE
}

\author{
Atiqah Najwa Zainuddin, Mazidah Mukri, Raimi Syazwani Asmuni, Nor Izzati Ibrahim and Nor Azizah Che Azmi
}

${ }^{1}$ Faculty of Civil Engineering, UiTM Pasir Gudang, 81750 PAsir Gudang, Johor

\begin{abstract}
Nano-clay is one of the innovation recently been studies as one of the enhancing materials to the soils. By adding a slight amount of nano-clay can improve some of behaviour such as hydraulic conductivity. Therefore, this research will investigate the performance of the hydraulic behaviour of different percentage of nano-clay in developing new soil liner design to be used in landfill. To complete the objectives, bentonite was pulverized by the process of high energy milling to obtain nano-bentonite. The milling sample is being analysed using Zeta Potential Analyzer and Field Emission Scanning Electron Microscope (FESEM). The laboratory studies were conducted by the determination geotechnical properties of the liquid limit, plastic limit, plasticity index shrinkage limit, particle density, compaction characteristic and also hydraulic conductivity value of raw bentonite mixed with $0 \% 1 \%, 2 \%$ and $3 \%$ of nano-bentonite. The laboratories result shows that the value of liquid limit, plastic limit, particle density and maximum dry density is increase in every addition of nano percentages meanwhile the value of plasticity index, optimum moisture content and hydraulic conductivity is decrease after adding nano-bentonite in the sample. The result shows the improvement of the soil by the geotechnical properties with addition of small amount of nano-bentonite.
\end{abstract}

\section{Introduction}

Nowadays, generation of the waste is getting higher as the number of population. Even by the incentive of the government by encouraging people to recycle and ruse, it does not affect the number of waste generated. At the end stage, the waste will end up at landfill. One of the problems that always arise in landfill is the leakage of the leachate. As a barrier from the leachate to penetrate into soil, bottom liner is implemented in landfill design. There are two types of bottom liner been used which is natural mineral liner and synthetic liner. Synthetic liner durability is limited in time while natural mineral liner can persist thousands of years (Stepniewski et al, 2000). Moreover, synthetic liner such as geomembrane made of polyethylene sheet are of the option to prevent the penetration of leachate, but their land decomposition period and sensitivity to the light made them less appropriate (Kananizadeh, 2011). Thus, natural mineral soil such as compacted clay is widely been used as the last barrier in landfill cross-sectional design.

As to be a good liner, some of the criteria needs to be fulfilled. One of the most important criteria is having low hydraulic conductivity (Rahman, 2010). Usually the design of hydraulic conductivity needs for soil liner should be less than $10^{-9} \mathrm{~cm} / \mathrm{sec}$ (Benson et al, 1984). Hydraulic conductivity is important. It plays role in liner to control and prevent in time from penetration of leachate for purpose of surrounding environmental.

Bentonite is a two to one layered smectite clay mineral with platy structure (Kananizadeh, 2011). It is widely being used in landfill as the characteristic of bentonite have low hydraulic conductivity. The nanobentonite is used due to good physical that has potential in improving the barrier. A study has been performed to design new soil liner design that meet the criteria of having low hydraulic conductivity.

\section{Materials}

\subsection{Bentonite Sample}

The bentonite used in this study is a manufacture production clay from C.T.Khoo Enterprise. The bentonite is a powder form of brown colour. The physical properties of bentonite are listed as in Table 1 . In general, this bentonite is classified as very high plasticity as it has of liquid limit of $345 \%$, plastic limit of 107 and plasticity index of 238. The basic geotechnical properties are conducted accordance to BS 1377:1990 Part 2.

Table 1. Properties of Bentonite

\begin{tabular}{|l|c|}
\hline \multicolumn{1}{|c|}{ Properties } & Values \\
\hline Particle Density $\left(\mathrm{G}_{\mathrm{s}}\right)$ & 2.46 \\
Liquid Limit $(\%)$ & 345 \\
Plastic Limit $(\%)$ & 107 \\
Plasticity Index (\%) & 230 \\
Maximum Dry Density & 1.073 \\
$\left(\mathrm{Mg} / \mathrm{m}^{3}\right)$ & \\
Optimum Moisture & 104.5 \\
Content $(\%)$ & \\
\hline
\end{tabular}

\subsection{Nano-bentonite Sample}

The nano-clay material used in this study is nanobentonite. To obtain the nano-bentonite, the bentonite powder is pulverized using high energy of ball machine. The range of the acceptable size is in (1-100) $\mathrm{nm}$ the bentonite specimen is loaded in bowl of Pulverisette Planetary Mill. The 500 balls of $1 \mathrm{~mm}$ is used and made of zicornia oxide. The time taken for milling each sample is 8 hours with speed of $400 \mathrm{rpm}$. The soil 
sample were then analysed by Zeta Potential Analyzer and Field Emission Scanning Electron Microscopy (FESEM). The Zeta Potential Analyzer is used to identify the percentage of nano-clay size in the sample. While the FESEM analyser is used for analysis of the soil particle. This milling process is considered as lowcost method in nano production [6]. However, this method does not produce uniform nano size particle as it only depends on the force exist while milling process.

\section{Experimental Testing}

\subsection{Sample Preparation}

The samples as shown in Table 2 were prepared where the sample of $0 \%$ nano is used as control sample. The percentage taken is based on the limitation of production nano and to find the optimum usage of nano-bentonite.

Table 2. Details of Soil sample

\begin{tabular}{|c|c|}
\hline Sample & $\begin{array}{c}\text { Nano-bentonite } \\
(\%)\end{array}$ \\
\hline $\mathrm{B}$ & - \\
\hline $\mathrm{B}+1 \% \mathrm{NB}$ & 1 \\
\hline $\mathrm{B}+2 \% \mathrm{NB}$ & 2 \\
\hline $\mathrm{B}+3 \% \mathrm{NB}$ & 3 \\
\hline
\end{tabular}

\subsection{Laboratories Testing}

The laboratories test is conducted to obtain the basic geotechnical properties of soil specimen bentonite mixed with different percentage of nano-bentonite such as Atterberg Limit, Particle Density, Compaction Characteristic and Hydraulic Conductivity. The test is conducted accordance to BS 1377:1990.

\section{Result and Discussion}

The table 3 show the summary properties of the 4 samples based on the laboratories test. While the Figure 1, Figure 2, Figure 3, Figure 4, Figure 5, Figure 6 and Figure 7 is discussion of the result obtain from the studies.

\begin{tabular}{|c|c|c|c|c|}
\hline Properties & Bentonite & $\begin{array}{c}\text { Bentonite } \\
+1 \% \text { Nanobentonite }\end{array}$ & $\begin{array}{c}\text { Bentonite + } \\
\text { 2\%Nanobentonite }\end{array}$ & $\begin{array}{c}\text { Bentonite + } \\
\text { 3\%Nanobentonite }\end{array}$ \\
\hline Liquid Limit (\%) & 345 & 408 & 434 & 455 \\
\hline Plastic Limit (\%) & 107 & 177 & 208 & 236 \\
\hline Plasticity Index (\%) & 238 & 231 & 226 & 219 \\
\hline Plasticity & $\begin{array}{c}\text { Very high } \\
\text { plasticity (CV) }\end{array}$ & Very high plasticity (CV) & $\begin{array}{c}\text { Very high plasticity } \\
\text { (CV) }\end{array}$ & $\begin{array}{c}\text { Very high plasticity } \\
\text { (CV) }\end{array}$ \\
\hline Shrinkage Limit (\%) & 32.87 & 27.84 & 14.39 & 7.92 \\
\hline Particle Density & 2.46 & 2.53 & 2.61 & 2.74 \\
\hline $\begin{array}{c}\text { Optimum Moisture } \\
\text { Content (\%) }\end{array}$ & 104.5 & 73.8 & 44 & 25.7 \\
\hline $\begin{array}{c}\text { Max Dry Density } \\
\left.\text { (Mg/m } \text { I }^{3}\right)\end{array}$ & 1.073 & 1.204 & 1.285 & 1.41 \\
\hline $\begin{array}{c}\text { Hydraulic Conductivity } \\
\text { (cm/sec) }\end{array}$ & $8.10 \times 10^{-12}$ & $1.19 \times 10^{-13}$ & $3.12 \times 10^{-16}$ & $3.38 \times 10^{-17}$ \\
\hline
\end{tabular}

\subsection{Nano-bentonite Analysis}

The FESEM image of original sample bentonite and sample which were milled for 8 hours is shown in Figure 1 (magnified 30000 times). Generally, it can be shown that the particle size of soil sample is change from platy structure to regular shaped of ball. Besides, the size of particle is reducing from 1 micrometre to (45-80) nm. This meets the target of the experiment to obtain nanosize in range of (1-100) $\mathrm{nm}$.

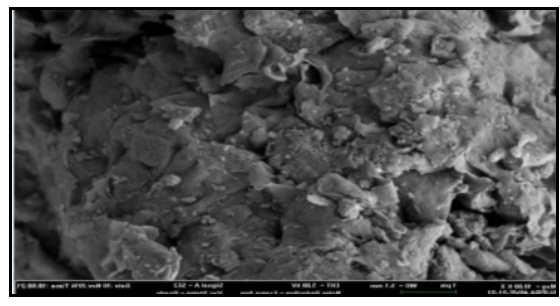

(a) Bentonite Sample

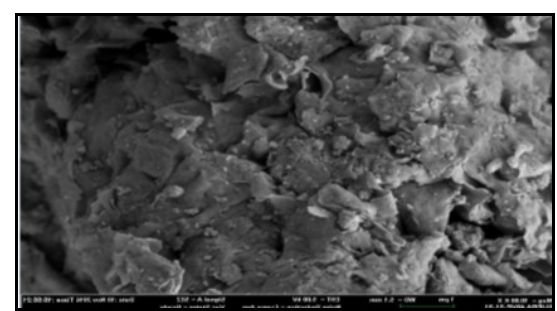

(b) Nano-bentonite Sample

Fig. 1. The FESEM image for (a) Bentonite Sample and (b) Nano-Bentonite Sample

\subsection{Physical Properties}

\subsubsection{Atterberg Limit and Shrinkage Limit}

Figure 2 shows the result of effect on the addition of nano-bentonite on Atterberg Limit. It can be seen that the increment of the liquid limit percentage will reduce the plasticity of the soil. The increases of the liquid limit is due to the area of nano particles. According to [11], it indicate that the reduction of plasticity shows that the soil is improving and it enhance the properties of the soil. 


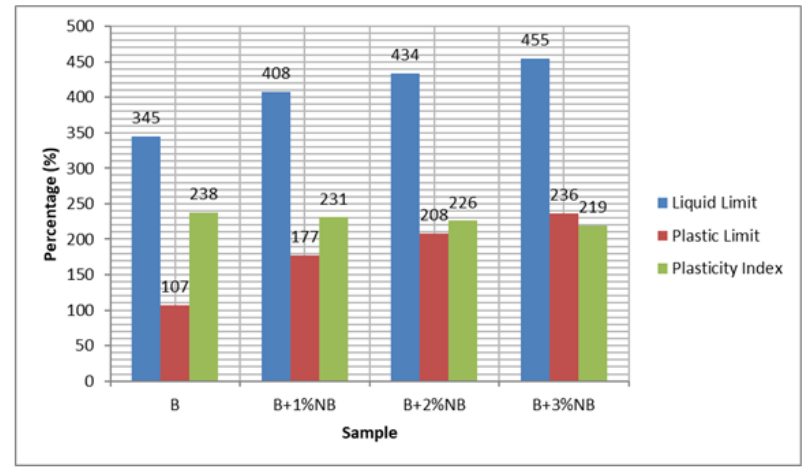

Fig. 2. The Atterberg Limit of Bentonite sample and addition of nano-bentonite

\subsubsection{Particle Density}

Figure 3 illustrate the particle density of the sample. The particle density of the sample is increasing as the nanobentonite is increasing. It shows that the nano-bentonite mixture is denser than the original bentonite sample. The particle density may also have related with clay content. The increment of clay content may result in changes of the void ratio thus affect the particle density.

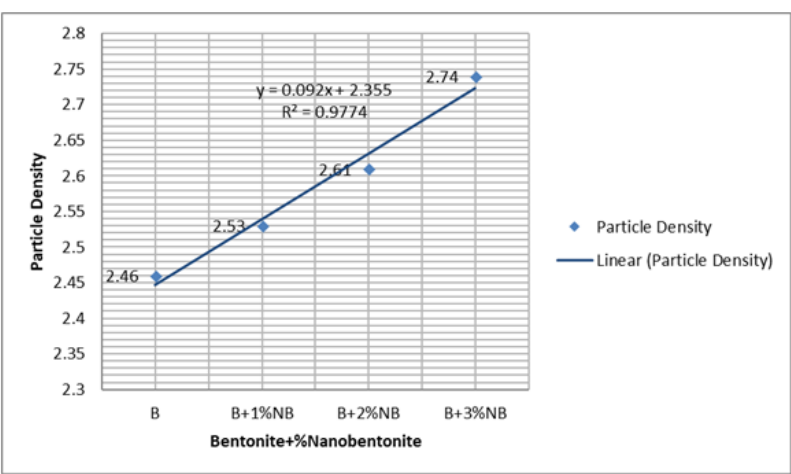

Fig. 3. The Particle Density of Bentonite sample and addition of Nano-bentonite

\subsection{Compaction Characteristic}

Figure $\mathbf{4}$ and Figure $\mathbf{5}$ illustrate the pattern of compaction characteristic of bentonite addition and addition of nano-bentonite. It shows that the maximum dry density is increasing proportionally to addition of nano-bentonite. However, the optimum moisture content is decrease as the addition of nano-bentonite is increasing. This behaviour happens as the particles is occupying the larges spaces.

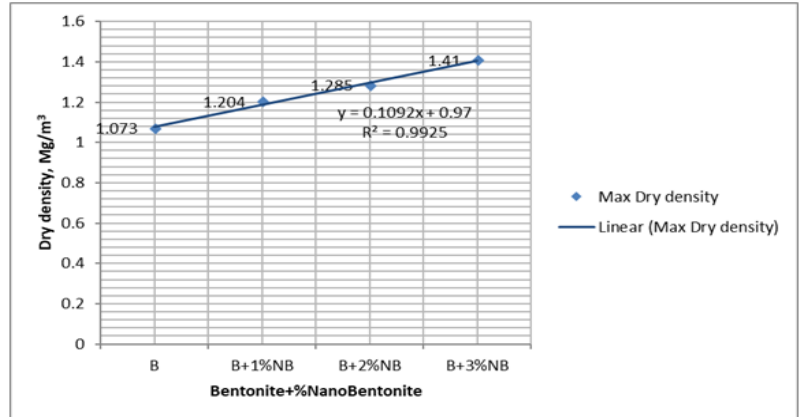

Fig. 4. The Maximum Dry Density of Bentonite sample and addition of Nano-Bentonite

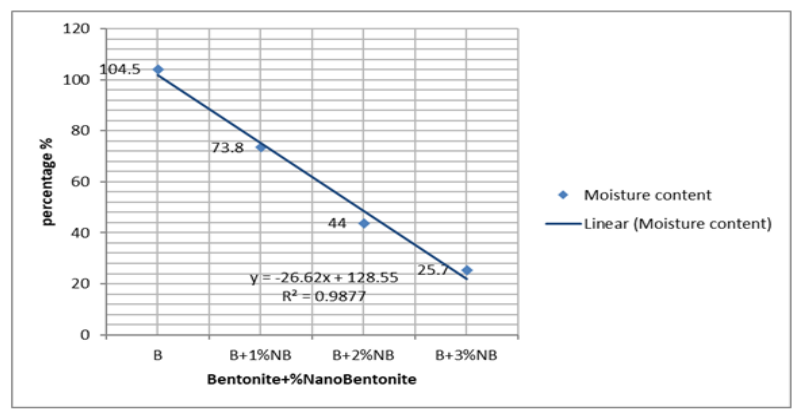

Fig. 5. The Optimum Moisture Content of Bentonite sample and addition of Nano-Bentonite

\subsection{Hydraulic Conductivity}

Figure 6 shows the effect on hydraulic conductivity by the addition of nano-bentonite in bentonite. It was observed that without the addition of the nano-bentonite the bentonite itself has achieved the hydraulic conductivity criteria of $10^{-9} \mathrm{~cm} / \mathrm{sec}$. It proved that bentonite is suitable to be liner material for landfill. However, with the addition of the nano-bentonite, the hydraulic conductivity performances keep on reducing. This reduction can be related with the particle size of the soil. According to (Zhang et. al, 2014), a dispersion of negative and positive charged of soil nano particles lead to disruption of soil structure and subsequently clog the soil pores and leads to reduction of hydraulic conductivity.

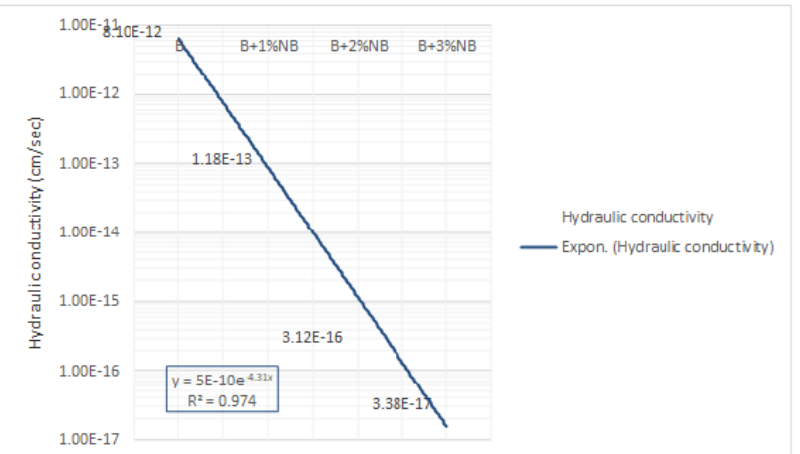

Fig. 6 The Shrinkage Hydraulic Conductivity of Bentonite sample and addition of Nano-bentonite 


\section{Conclusion}

This paper provides an overview on effect of the nanobentonite on the properties of original bentonite. Based on the result, it shows that the addition of nano-bentonite improved the properties of the bentonite. Even by a small amount, it expeditiously influences the soil improvement. It shows that the liquid limit, plastic limit and maximum dry density is increasing while the plasticity index and optimum moisture content is decreasing. It proved that application of nano-bentonite was significant in reducing the hydraulic conductivity value.

\section{References}

1. Ab. Malek, M.I., \& M. G. Shaaban. Landfill Common Method and Practices of Solid Waste Disposal in Malaysia, (2008)

2. B. C. H. Benson, A. Member, H. Zhai, \& X. Wang, Estimating Hydraulic Conductivity of Compacted Clay Liners, 120(2), 366-387 (1994)

3. B. M. Das, Principle of Geotechnical Engineering. 7 $^{\text {th }}$ ed. USA: Cengage learning, (2010)

4. EPA. (2001). Geosynthetic Clay Liners Solid Waste Landfills.

5. D.G. Fredlund, H. Rahardjo,. Soil Mechanics for Unsaturated Soils, (1993)

6. N. Khalid, M.F. Arshad, M. Mukri, K. Mohamed, \& F. Kamarudin, The Properties of Nano Kaolin Mixed with Kaolin, (2014)

7. Z.C. Moh, \& M.F. Mazhar. Effects of Method of Preparation on Index Properties of Lateritic Soil. In proceedings of the Specialty Session. Engineering Properties of Lateritic Soils, 1, 23-26 (2009)

8. J.P. Power, \& C.J. Herridge, Construction Dewatering and Groundwater Control New Method and Application, (2007)

9. O.M.E. Taha, \& M.R. Taha, Volume Change and Hydraulic Conductivity of Soil-bentonite Mixture. Journal of Civil Engineering, 9(1), 43-53 (2015)

10. M.R.Taha, W.Z.W. Yaacob, A.R. Samsudin, \& J. Yaakob, Groundwater Quality At Two Landfill Sites In Selangor, Malaysia, 57, 13-18 (2011)

11. M.R. Taha, Geotechnical Proprtiesod Soil Ball milled Soil Mixture. Proc. $3^{\text {rd }}$ Symp on Nanotechnology in Construction, (2009)
12. E.A. Tuan Mat, Intergriting Waste Minimisation \& Recycling in Solid Waste Management in Malaysia. Proceedings Waste Management Conference and Exhibition, (2007)

13. R. Whitlow, Basic Soil Mechanics. $4^{\text {th }}$ ed. Singapore: Prentice Hall, (2004)

14. N. Yahaya, Keynote Address. Waste Management Conference and Exhibition 2007. Department of National Solid Waste Management. Ministry of Housing and Local Government, (2007)

15. M.N.M. Yunus, Waste Incineration Challenge and Possible Application in Malaysia. Institute for Nuclear Technology Research (MINT), Bangi, Selangor, (2000) 